\title{
Measurement of Brain Activity Rate Based on Electroensefalographical Signals on Smokers
}

\author{
Herry Setiawan \\ Computer Engineering Study Program Polytechnic of South Aceh \\ Tapaktuan, Indonesia \\ herysetiawan88@poltas.ac.id
}

\section{ARTICLE INFO}

Article history:

Accepted

Keywords:

Electroencephalography

Brain

Prefrontal cortex

Nicotine

Orbitofrontal cortex

\section{ABSTRACT}

\begin{abstract}
Indonesia as a country with $255,182,144$ people (Central Bureau of Statistics, 2015) with the number of smokers reached 46.16 percent in the third rank with the largest number of smokers in the world after China and India, there are some elements in cigarettes one of them is nicotine, it will be one of the addictive additives. It's why smokers want to continue smoking cigarettes on a regular basis. It bounds to the brain receptors and in other organs. Increased activity in the orbitofrontal area of the cortex occurs when a smoker wants a cigarette, while in the prefrontal cortex experiences an increase in activity when smokers smoke cigarettes. Increased activity in the area will produce electrically along the scalp that can be measured using Electroencephalography (EEG). The voltage difference of the ion current will give the addiction level information to the cigarette so it can be classified. Classification is done in 4 classes namely low dependence, Moderate dependence and high dependence. From the results of the study we found that the level of brain activity of the frontal cortex increased. $52 \%$ of the 40 sampled data showed the highest increase in activity by reaching $53.17 \%$ in the highly dependent addiction category.
\end{abstract}

Copyright (C) 2018 Politeknik Aceh Selatan. All rights reserved.

\section{Introduction}

Indonesia as a country with $255,182,144$ populations [3] with the number of smokers reaching 46.16 percent [4] keeping the third rank with the largest number of smokers in the world after China and India. The results of the Research and Development Agency of the Ministry of Health in 2010 showed that deaths from diseases associated with tobacco occurred 190,260 people or about $12.7 \%$ of all deaths in the same year in Indonesia. The figure will continue to rise where WHO predicts 10 million deaths caused by cigarettes in 2030 as cigarette consumption increases.

Based on Government Regulation no. 109 of 2012 on the safeguarding of ingredients containing additives in the form of tobacco products for health, cigarettes is one of the tobacco products intended to be burned or smoked, including clove cigarettes, white cigarettes, cigars or other forms resulting from Niotiana Tabacum or synthetic plants the smoke contains nicotine and tar. Nicotine is one of the addictive additives [1] it's why smokers want to continue smoking cigarettes on a regular basis. It is bound to the brain receptors and in other organs [2] some of these parts are Cardiovascular system, Gastrointestinal system, Peripheral nervous system, Adrenal medulla, Exocrine glands and Central nervous.

Central nervous system is a part of the nervous system located within the cheek and spine. In the case of cigarette addiction, the most influencing part of the central nervous system is the orbitofrontal area of the cortex and the prefrontal cortex [5]. Increased activity in the orbitofrontal area of the cortex occurs when a smoker wants a cigarette, while in the prefrontal cortex experiences an increase in activity when smokers smoke cigarettes. Increased activity in the area will produce electrically along the scalp that can be measured using Electroencephalography (EEG). The EEG can 
record and measure the voltage fluctuations produced by ion currents within the brain neurons [6]. The voltage difference of the ion currents will give the cigarette addiction rate information so it can be classified using Neural network [7][8][9].

Measurement of EEG data is done in 3 classes namely low dependence, Moderate dependence and high dependence. In accordance with the application of the Fagerström Test for Cigarette Dependence (FTCD)[10]. FTCD is a cigarette-dependent measurement instrument that is widely used clinically [11].

\section{Literature Review}

\subsection{Cigarette Dependency}

Processing is the most crusial stage considered to have a significant influence on the shape and size of the resulting tea powder, where the nutmeg pulp is physically transformed into small sections which then become tea powder.

Cigarettes are addictive. During this time, cigarette dependence is always associated with nicotine. It is a substance in cigarette smoke that is considered the most important role in making cigarettes become addictive. Therefore, cigarette dependence is often represented by nicotine addiction in nicotine in cigarettes creating a pleasant feeling and dampening anxiety. In the short term, cigarettes also increase concentration and performance in working. Both of these can induce cigarette addiction.

In addition, smokers who try to quit smoking usually fail because they cannot deal with the withdrawal effect of quitting smoking suddenly, that is tired, anxious, too sensitive to stimulation, and bad mood, so smokers with withdrawal effects tend to engage in smoking to dampen the effect [12]. Nicotine in cigarettes causes addiction through the induction of dopamine production. It interacts with nicotinic acetylcholine receptors in the mesolimbic areas of the brain. This interaction will lead to the release of dopamine in the places involved in the regulation of information, memory, and emotions. The increase in dopamine levels in the mesolimbic areas of the brain causes feelings of addiction.

Nicotine addiction in cigarettes has phases and criteria that are almost identical to drug addiction. Nicotine addiction occurs in 3 phases, namely the acceptance and maintenance of nicotine consumption habits, the emergence of withdrawal symptoms when stopped consuming, and the tendency to recur. Nicotine addiction criteria include the following.

a. Primary Criteria

Namely, the use of controlled and compulsive, the emergence of psychoactive effects, and the emergence of behavior due to drug stimulation (drug-reinforced behavior).

b. Additional Criteria

That is behavior such as regular use patterns, continued use despite already knowing the harmful effects, relapse during stop consuming, and the emergence of excessive desire to consume (craving).

Lately, the use of nicotine addiction as a term that represents dependence on cigarettes is being reviewed. According to Fagerström (2012), although nicotine is the substance that most play a role in causing dependence on cigarettes, there are many other substances in cigarettes that have the potential to cause similar things. Acetaldehyde, one of the content of cigarette smoke, can cause dependence through inhibition of monoamine oxidase (MAO) enzyme, so dopamine levels increase [13]. In addition, the efficacy of replacement nicotine therapy to help quit smoking is considered moderate even if the amount of nicotine replacement has been replacing the amount of nicotine.

\subsection{Orbitofrontal area of cortex and prefrontal cortex}

The prefrontal cortex (PFC) is the anterior portion of the frontal lobe in the brain, located in front of the motor area and the premotor. The prefrontal cortex in the brain is shown in figure 2.1. 


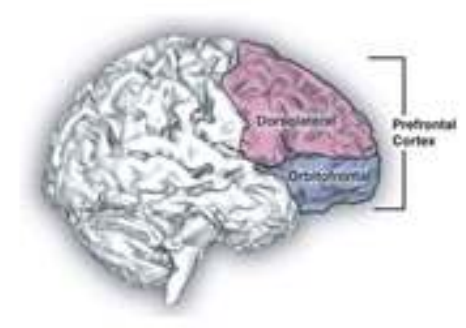

Figure 2.1 The location of the orbitofrontal cortex and the prefrontal cortex in the brain [17]

There are three possible ways to define the prefrontal cortex:

- As a granular frontal cortex

- As a core projection zone of mediodorsal thalamus

- As part of the frontal cortex whose electrical stimulation causes no movement

Orbitofrontal cortex (OFC) is part of the prefrontal cortex that receives projections of the magnocellular, medial nucleus (midway) of the mediodorsal thalamus. Although this section includes many mysteries, the OFC is part of the decision-making cognitive process with its natural role as the 'profit-loss' calculator of an action based on constructs of rewards and punishments that can be learned. The prefrontal area is the frontal part of the frontal lobes, the largest cortical lobe that contains five major areas for neuropsychiatric function (planning, organizing, problem solving, selective attention, personality) and motor functioning and mediates higher cognitive functions including emotion and behavior. In this region the brain has been involved in the planning of complex cognitive behaviors, personality expressions, decision-making and moderate social behavior are correct. The basic activity of this region is that the brain is regarded as an orchestration of thought and action according to internal goals.

Behavioral issues associated with frontal lobe damage can be roughly classified into 5 overlapping groups::

1. Problems of starting; appear in the form of decreased spontaneity, decreased productivity, decreased average behavior performed, or decreased or loss of initiative.

2. Difficulties in making mental or behavioral shifts. Problems that can occur are in attention, change of movement, or flexibility in attitude, is in the sphere of perseveration or rigidity (rigidity). Perseveration refers to the repeated extension or resumption of an action or activity sequence, or repetition of the same or similar response to a variety of questions, tasks, or situations.

3. Problems in stopping; in the activity of stopping or modulating the behavior that is being performed-appearing in the form of impulsivity, overreaction, disinhibition, and difficulty withstanding the wrong or unwanted response, especially when the response has a strong association value or is a part of chain response.

4. Deficient self-awareness. Produced an inability to perceive wrong performance (error), to appreciate the impact made on others, to measure social situations well / fit, and to empathize with others.

A congrete attitude, or loss of abstract attitude. This indicates a person's inability to separate from the surroundings in a lateral manner in which objects, experiences, and behaviors are included in clear values. Patients become unable to plan and predict or maintain (goal-directed behaviors).

\subsection{Measurement with Fagerström Instrument Test for Cigarette Addiction}

During this time, various instruments have been developed to measure compensation for cigarettes. The instrument is a questionnaire with several questions. The contents of the instruments include the following.

a. Recurring and compulsive use

b. Difficulty controlling cigarette use

c. The feeling of wanting to get a cigarette caused by certain things, such as desire or feeling relax after smoking. 
d. Confidence in the efficacy of cigarettes is done on the effect of strengthening (reinforcement) obtained from smoking.

e. A very important manifestation embodied in the form of a being or withdrawal

The Decisional Balance is an instrument for measuring influences such as the balance between simplicity and disagreement, and the Self-Efficacy / Temptation Scale to measure respondents' beliefs about their ability to quit smoking and resist the temptation to return to smoking [14], and the Fagerström Tests for Nicotine Addiction it was recently proposed to rename the Fagerström Test for Cigarette Addiction [13]. Fagerström Test for Cigarette Dependence (FTCD) is an impact measuring instrument on clinically used cigarettes. FTCD is already on various clinical guidelines by agencyagencies health, among others by Western Australian State Health Department (2011), European Medicines Agency (2007), and National Health Service (2011) in UK. The FTCD is expected to be practical because it can measure addiction by a small amount, a fairly easy system, and its psychometric properties are still adequate [14]. FTCD basically measures cigarette addiction based on nicotine (smoking) exposure, smoking difficulties, and smoking urgency [15]. FTCD consists of 6 questions. Each question has 2-4 choices of answers with certain points.

Measurement horizontally with FTCD on total score of respondents. The greater the test score the greater the respondents on cigarettes [10]. FTCD classifies cigarette addiction to five levels, very low dependence, low dependence, moderate dependence, high dependence, and very high dependence.

\subsection{Identifying different patterns of brain activity}

The brain is an interesting part of humans, brain activity will be produced electrical activity. To measure it can be done with Electroencephalogram (EEG). EEG can detect any abnormalities of the brain. This action uses a special sensor that is the electrode mounted on the head and connected through a cable to the computer. The EEG will record the electrical activity of the brain, which is represented in the form of a wave line.

There are two methods of measuring brain signals: Invasive and non-invasive [16]. Invasive approach Requires physical implants of electrodes in humans or animals, thus enabling single neuron measurements while noninvasive approaches utilize magnetic resonance imaging (MRI) and EEG technology to perform measurements.

There are several types of electrical brain waves that can be generated from the EEG test, including alpha waves, beta waves, delta waves and theta waves.

\section{Method}

The research stages include several steps as shown in figure 3.1.

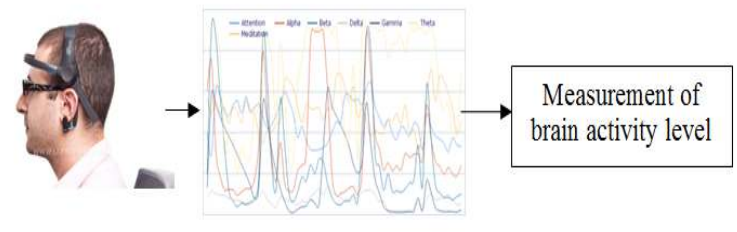

Figure 3.1 Research Stages

From figure 3.1, the research phase consists of several steps, the first stage is the sampling of brain signals in all participants. All participants are conditioned into 3 conditions that is, without smoking, want to smoke by showing the visualization of people smoking and smoking at the time of data retrieval. The second stage is signal separation signal into 5 that are, signal alpha, beta, theta, gamma and delta. The next stage is to calculate increasing in the activity of the frontal cortex of each sample of low dependence, moderate dependence and high dependence. In this study, the observed changes are signals of alpha, beta, delta, theta and gamma produced by the brain activity patterns in the prefrontal cortex. Framework the concept of research is shown in figure 3.2. 


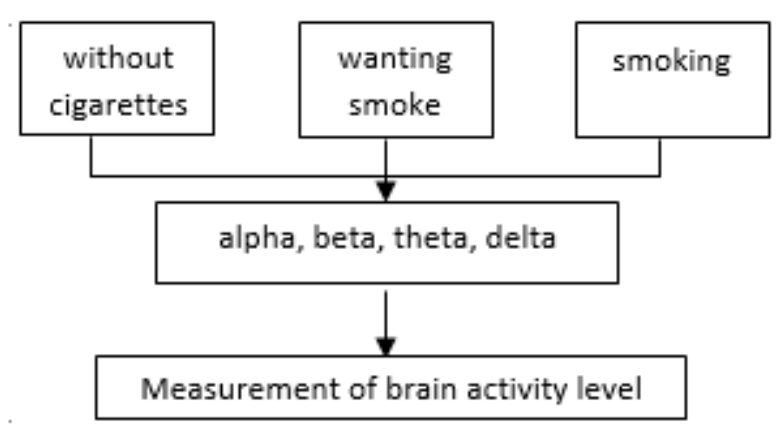

Figure 3.2.Schematic the concept of research

From Figure 3.2 shows that the brain signal data retrieval is done with 3 conditions there are, without smoking, wanting to smoke and smoking. These three conditions will give different activity patterns that will be measured with EEG, the result is a 5-piece type of signal which is then made predictions on other participants for the level of cigarette addiction experienced, thus a warning for participants to quit smoking.

In this research data collection technique that writer used survey technique at smoker that is in the form of direct observation to every participant. EEG data is captured for one minute each before and during cigarette smoking.

\section{Results And Discussion}

Data collection was done as many as 25 people at random, consisting of several categories of cigarette addiction rate. Data from sample and category of addiction levels according to FTCD is shown in table 1.

Table 1 Result of FTCD Questionnaire

\section{No Sample code Total Score Level of addiction}

\begin{tabular}{rlll}
\hline 1 & B001 & 8 & highly dependent \\
\hline 2 & B002 & 7 & highly dependent \\
\hline 3 & B003 & 5 & moderately dependent \\
\hline 4 & B004 & 3 & minimally dependent \\
\hline 5 & B005 & 2 & minimally dependent \\
\hline 6 & B006 & 7 & highly dependent \\
\hline 7 & B007 & 5 & moderately dependent \\
\hline 8 & B008 & 8 & highly dependent \\
\hline 9 & B009 & 2 & minimally dependent \\
\hline 10 & B010 & 9 & highly dependent \\
\hline 11 & B011 & 4 & moderately dependent \\
\hline 12 & B012 & 9 & highly dependent \\
\hline 13 & B013 & 6 & moderately dependent \\
\hline 14 & B014 & 3 & minimally dependent \\
\hline 15 & B015 & 8 & highly dependent \\
\hline 16 & B016 & 4 & moderately dependent \\
\hline 17 & B017 & 5 & moderately dependent \\
\hline 18 & B018 & 8 & highly dependent \\
\hline 19 & B019 & 6 & moderately dependent \\
\hline 20 & B020 & 0 & minimally dependent \\
\hline 21 & B021 & 5 & moderately dependent \\
\hline & & &
\end{tabular}




\section{No Sample code Total Score Level of addiction}

\begin{tabular}{llll}
\hline 22 & B022 & 6 & moderately dependent \\
\hline 23 & B023 & 7 & highly dependent \\
\hline 24 & B024 & 7 & highly dependent \\
\hline 25 & B025 & 5 & moderately dependent \\
\hline
\end{tabular}

From table 1 it can be seen that the results of questioners from 25 samples are grouped into 3 categories: 10 samples for moderately dependent, 5 samples minimally dependent and the remaining is highly dependent. Retrieval of EEG smoker data is taken with two situations, first situation before smoking and during smoking. Results from prior smoking data are shown in figure 4.1.

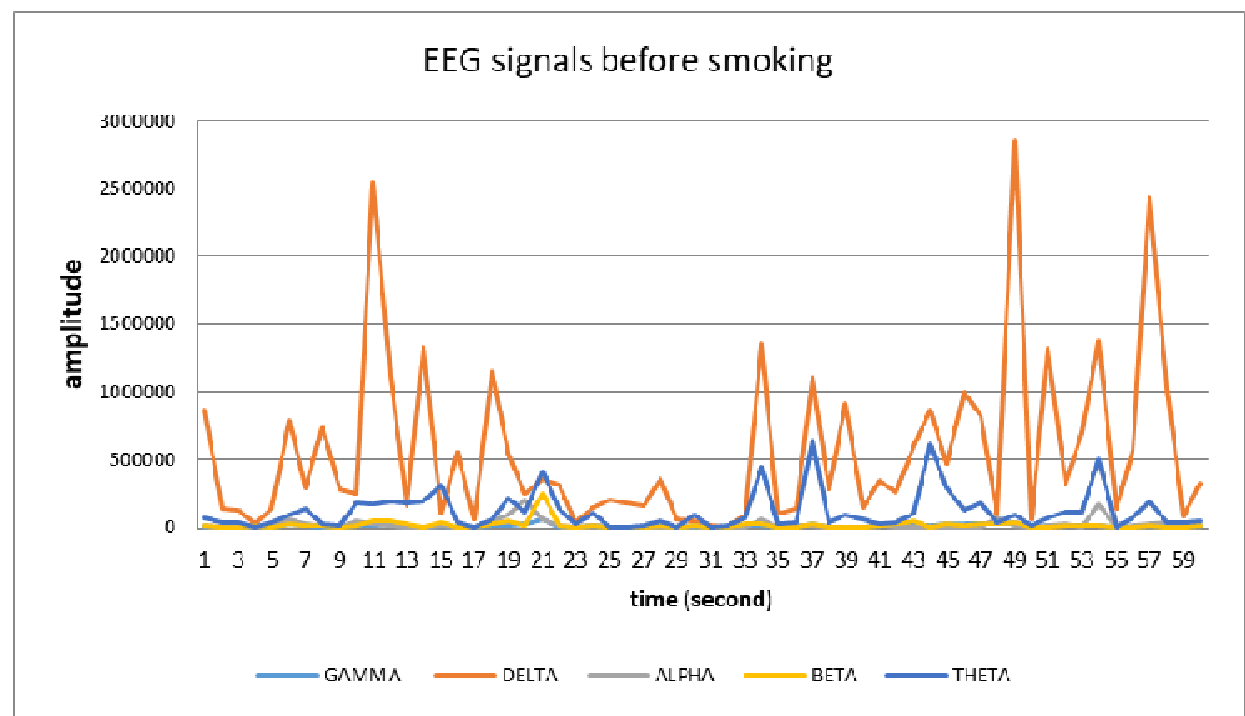

Figure 4.1 EEG sample B001 data before smoking

Taking data when smoking is done for one minute. Samples are invited to smoke and enjoy cigarettes. The results of EEG data on smoking are shown in figure 4.2.

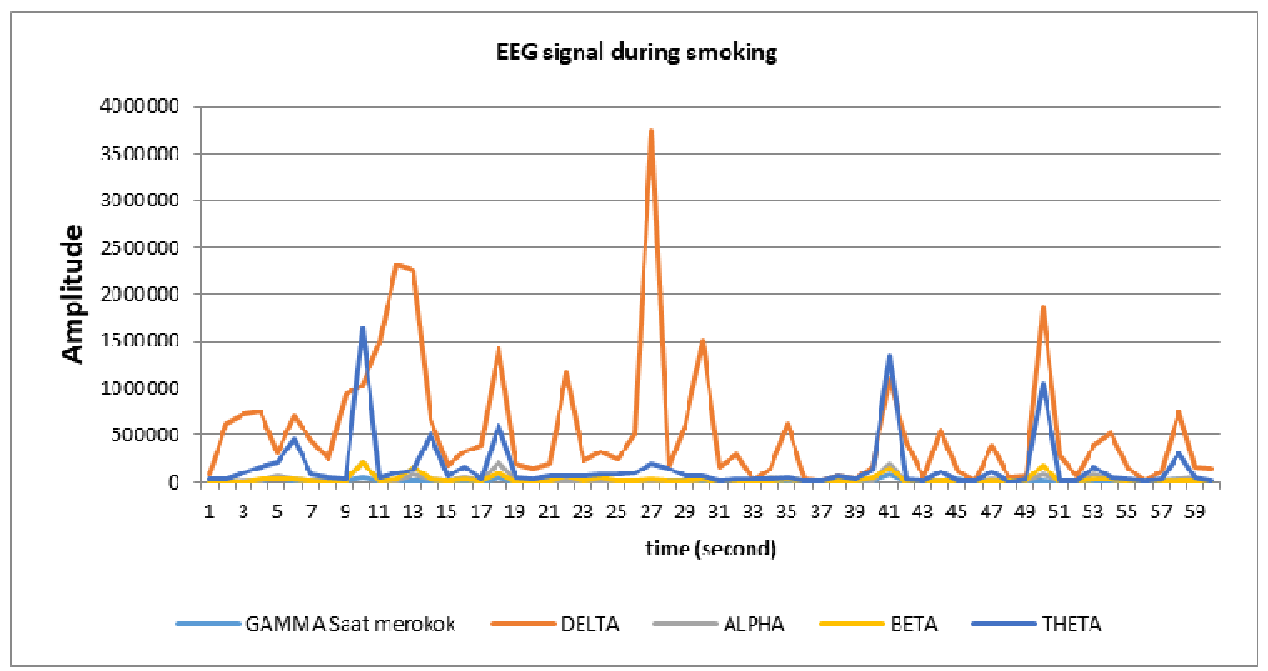

Figure 4.2. EEG sample B001 data during smoking 
Table 2 results of EEG data before and during smoking

\begin{tabular}{|c|c|c|c|c|c|c|c|c|c|c|c|c|c|}
\hline \multirow{2}{*}{ No } & \multirow{2}{*}{$\begin{array}{c}\text { Sample } \\
\text { code }\end{array}$} & \multicolumn{5}{|c|}{ Average score before smoking } & \multicolumn{5}{|c|}{ The average value of smoking } & \multirow{2}{*}{\begin{tabular}{|c|} 
percentage \\
increase / \\
decrease in frontal \\
cortex activity (\%)
\end{tabular}} & \multirow{2}{*}{ explanation } \\
\hline & & GAMMA & DELTA & ALPHA & BETA & THETA & GAMMA & DELTA & ALPHA & BETA & THETA & & \\
\hline 1 & B001 & 13151.3 & 553031.5 & 23730.8 & 20248.6 & 119962.8 & 11975.8 & 544029.6 & 27234.6 & 25978.8 & 150520.3 & 3.90 & increase \\
\hline 2 & B002 & 16199.8 & 510212.6 & 36029.8 & 19708.2 & 132637.3 & 5671.9 & 587413.4 & 22842.5 & 12849.8 & 118107.6 & 4.30 & increase \\
\hline 3 & B006 & 3944.9 & 619538.5 & 42678.8 & 17975.0 & 168979.8 & 6758.4 & 696688.7 & 32161.0 & 22091.8 & 130916.3 & 3.99 & increase \\
\hline 4 & B008 & 4386.3 & 467507.8 & 22821.2 & 18380.2 & 94884.4 & 13008.7 & 966882.2 & 65277.3 & 36925.7 & 216076.8 & 53.17 & increase \\
\hline 5 & B010 & 3046.2 & 533685.4 & 65901.7 & 5968.8 & 436667.7 & 4064.4 & 841793.2 & 130939.8 & 16085.7 & 385008.3 & 24.14 & increase \\
\hline 6 & B012 & 6030.0 & 636238.7 & 97841.4 & 20545.6 & 379414.1 & 7038.7 & 841501.4 & 36033.6 & 21843.2 & 201944.8 & 2.86 & reduction \\
\hline 7 & B015 & 10722.1 & 625530.8 & 39248.5 & 30013.8 & 161274.8 & 15463.6 & 661345.3 & 28009.4 & 21949.6 & 138785.8 & 0.14 & reduction \\
\hline 8 & B018 & 11048.1 & 696676.6 & 69635.6 & 21890.5 & 279176.0 & 6453.7 & 715451.4 & 61488.0 & 25045.2 & 194686.9 & 7.51 & reduction \\
\hline 9 & B023 & 8930.0 & 473552.9 & 21654.9 & 13159.5 & 86088.3 & 7254.7 & 164763.6 & 9273.1 & 8719.3 & 41902.4 & 160.18 & reduction \\
\hline 10 & B024 & 12460.7 & 752843.2 & 53402.0 & 36679.2 & 198674.2 & 13272.8 & 803896.6 & 45114.2 & 25434.6 & 219361.1 & 4.79 & increase \\
\hline 11 & B004 & 125872.8 & 868342.6 & 162564.9 & 90366.2 & 451297.9 & 47213.2 & 986835.2 & 103491.7 & 79981.5 & 318823.1 & 10.55 & reduction \\
\hline 12 & B005 & 10002.6 & 723618.0 & 54040.7 & 22448.4 & 492951.6 & 5612.1 & 739799.8 & 142932.2 & 12585.4 & 350782.3 & 4.10 & reduction \\
\hline 13 & B009 & 126477.4 & 726341.1 & 180788.3 & 126931.1 & 616206.1 & 135485.8 & 693577.0 & 125284.7 & 119676.6 & 695232.1 & 0.42 & reduction \\
\hline 14 & B014 & 9103.2 & 209891.1 & 11686.3 & 9669.2 & 42326.2 & 9486.3 & 208640.3 & 17871.5 & 10862.0 & 49117.5 & 4.49 & increase \\
\hline 15 & B020 & 5044.5 & 847918.6 & 68220.9 & 15526.5 & 236135.8 & 16115.0 & 795528.1 & 78064.3 & 36369.4 & 296633.8 & 4.08 & increase \\
\hline 16 & B003 & 5940.8 & 722306.3 & 53016.7 & 17793.6 & 184852.5 & 29321.6 & 756707.1 & 89405.4 & 54243.1 & 482539.8 & 30.33 & increase \\
\hline 17 & B007 & 157203.0 & 707410.9 & 119893.3 & 127715.0 & 538700.8 & 5026.5 & 622948.1 & 46961.4 & 15116.0 & 160421.0 & 94.12 & reduction \\
\hline 18 & B011 & 15773.3 & 942574.2 & 56793.8 & 54370.5 & 249872.9 & 19288.2 & 603353.8 & 35862.5 & 19452.8 & 154817.7 & 58.43 & reduction \\
\hline 19 & B013 & 3583.4 & 1054591.0 & 46259.0 & 18862.5 & 205095.0 & 4735.6 & 886381.6 & 48939.5 & 20567.5 & 249455.1 & 9.78 & reduction \\
\hline 20 & B016 & 9221.8 & 391361.4 & 29306.0 & 21974.2 & 129591.8 & 10690.6 & 433440.6 & 23414.9 & 20897.9 & 117303.9 & 4.01 & increase \\
\hline 21 & B017 & 8640.4 & 845967.1 & 126318.1 & 19122.7 & 304313.9 & 14725.2 & 918886.7 & 57287.4 & 30028.8 & 260863.8 & 1.76 & reduction \\
\hline 22 & B019 & 14191.8 & 683171.8 & 60624.4 & 21747.0 & 474377.9 & 9104.9 & 881428.0 & 79514.0 & 27447.9 & 226901.9 & 2.43 & reduction \\
\hline 23 & B021 & 17345.6 & 311840.8 & 26010.2 & 16095.4 & 87772.6 & 18634.5 & 570646.6 & 36026.1 & 22001.6 & 144168.7 & 42.00 & increase \\
\hline 24 & B022 & 12183.3 & 280447.6 & 24914.4 & 23423.6 & 84207.2 & 14363.8 & 587225.1 & 35008.9 & 16955.2 & 126285.7 & 45.48 & increase \\
\hline 25 & B025 & 12068.8 & 810975.7 & 38584.3 & 19580.6 & 156057.2 & 13126.5 & 907093.0 & 30627.1 & 32893.0 & 176031.8 & 10.56 & increase \\
\hline
\end{tabular}

From the data table 2 shows 13 samples experienced an increase in activity in the frontal cortex of the brain or $52 \%$ of the sample amount at the time of smoking. Increased brain activity tends to occur in the sample with the category of weight and medium addiction as much as 11 remaining samples in the category of minimal or low addiction.

\section{Conclusion}

From the results of the study we found that the level of brain activity of the frontal cortex increased. $52 \%$ of 40 samples data showed the highest increasing in activity by reaching $53.17 \%$ in highly dependent addiction category. Surely this research is still many shortcomings. Future development will be classified by addiction rate by comparing data from EEG with questioner result. EEG data classification can be done with the application of Neural Network method. So, the result is accurate.

\section{References}

[1] E. S. Yuni, "Identifikasi nikotin dari daun tembakau (nicotiana tabacum) kering dan uji efektivitas ekstrak daun tembakau sebagai insektisida penggerek batang padi (scirpophaga innonata)," Fakultas matematika dan ilmu pengetahuan alam universitas negeri semarang, 2006.

[2] anonim, "Farmakologi nikotin dan prinsip adiksi," no. Universitas Gajahmada, Yogyakarta: Universitas Gajahmada, 2015, p. 23.

[3] Badan Pusat Statistik, Result of the 2015 Intercensal Population Census. 2015.

[4] Pusat Data dan Informasi Kementerian Kesehatan RI, "InfoDATIN : Hari Tanpa Tembakau Sedunia," Kemenkes, p. 12, 2013.

[5] T. Lewis, "Brain Circuitry Behind Cigarette Cravings Revealed," livescience.com, 2013. .

[6] W. Rosenberg, T. Chanwimalueang, V. Goverdovsky, and D. Sharp, "Smart Helmet: Wearable Multichannel ECG and EEG," IEEE J. Transiational Eng. Heal. Med., vol. 4, no. February, 2016. 
[7] H. Setiawan and E. M. Yuniarno, "Features extraction of palm vein image using phase symmetry," Proc. - 2015 4th Int. Conf. Instrumentation, Commun. Inf. Technol. Biomed. Eng. ICICI-BME 2015, pp. 59-64, 2016.

[8] H. Setiawan, "Biometric Recognition based on Palm Vein Image Using Learning Vector Quntization," pp. 5-9.

[9] H. Setiawan and N. Saputri, "Biometric Recognition Based on Acoustic Features," in Seminar Nasional Teknologi Rekayasa (SNTR) III Tahun 2016, 2016, pp. 126-129.

[10] S. Kassim, S. Kassim, M. Salam, and R. Croucher, "Validity and Reliability of the Fagerstrom Test for Cigarette Dependence in a Sample of Arabic Speaking UK-Resident Yemeni ... Validity and Reliability of the Fagerstrom Test for Cigarette Dependence in a Sample of Arabic Speaking UK-Resident Yemeni Khat ," vol. 13, no. April 2012, pp. 2010 2013, 2014.

[11] I. B. Artana and I. N. Rai, "Tingkat Ketergantungan Nikotin Dan Faktor-Faktor Yang Berhubungan pada Perokok di Desa Penglipuran 2009," IGN Bagus Artana, IB Ngurah Rai, vol. 11, no. 1-9, 2010.

[12] N. Benowitz, "Nicotine Addiction," N. Engl. J. Med., vol. 362, no. 24, pp. 2295-2303, 2010.

[13] FAGERSTRÖM K:, "Determinants of tobacco use and renaming the FTND to the Fagerström Test for Cigarette Dependence," Nicotine Tob Res 14 75-78, 2012.

[14] W. (Eds. . James, Larry, O'Donohue, The Primary Care Toolkit Practical Resources for the Integrated Behavioral Care Provider, 1st ed. New York: Springer-Verlag, 2009.

[15] US Department of Health and Human Services, "Healthy People 2010: Understanding and Improving Health," Heal. San Fr., vol. 2nd., p. 62 p., 2000.

[16] E. A. Larsen and A. I. Wang, "Classification of EEG Signals in a Brain- Computer Interface System," no. June, 2011.

[17] S. Neena, "The Brain's Cerebral Cortex (Neocortex)," 2011. . 